\title{
Local hemostatic measures in anticoagulated patients undergoing oral surgery. A systematized literature review ${ }^{1}$
}

\author{
Fábio Wildson Gurgel Costa ${ }^{\mathrm{I}}$, Rodrigo Rodrigues Rodrigues" ${ }^{\mathrm{II}}$, Luzia Hermínia Teixeira de Sousa ${ }^{\mathrm{II}}$, Francisco Samuel Rodrigues \\ Carvalho $^{\text {III }}$, Filipe Nobre Chaves ${ }^{\mathrm{IV}}$, Clarisse Pessoa Fernandes ${ }^{\mathrm{IV}}$, Karuza Maria Alves Pereira ${ }^{\mathrm{V}}$, Eduardo Costa Studart Soares ${ }^{\mathrm{VI}}$ \\ IPhD, Assistant Professor, Division of Stomatology and Oral Surgery, UFC, Campus Sobral, Fortaleza-CE, Brazil. Conception, design, intellectual and \\ scientific content of the study, manuscript writing, critical revision.

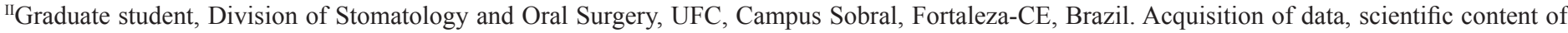 \\ the study, manuscript writing. \\ IIIDDS, Collaborative Professor, Division of Stomatology and Oral Surgery, UFC, Campus Sobral, Fortaleza-CE, Brazil. Conception, design, intellectual \\ and scientific content of the study, manuscript writing, critical revision. \\ ${ }^{\mathrm{IV}}$ Fellow Master degree, Postgraduate Program in Dentistry, Dental Clinic Area, Division of Stomatology, UFC, Fortaleza-CE, Brazil. Acquisition of \\ data, scientific content of the study, manuscript writing. \\ ${ }^{\mathrm{V}} \mathrm{PhD}$, Associate Professor, Division of Oral Pathology, UFC, Campus Sobral, Fortaleza-CE, Brazil. Conception, design, intellectual and scientific \\ content of the study, manuscript writing, critical revision \\ ${ }^{\mathrm{V}} \mathrm{PhD}$, Full Professor, Division of Oral Surgery, UFC, Fortaleza-CE, Brazil. Conception, design, intellectual and scientific content of the study, \\ manuscript writing, critical revision
}

\begin{abstract}
PURPOSE: To conduct a systematized review of the literature about the main local hemostatic measures to control postoperative bleeding in anticoagulated patients.

METHODS: A systematized review of literature was performed in the electronic database Medline (PubMed) without restriction of the publication date. The eligibility criteria were studies involving maintenance of the anticoagulant therapy, prospective studies, retrospective studies, randomized clinical trials, controlled clinical studies, comparative studies, multicentric studies or case-control studies. Studies discontinuing anticoagulant therapy, case reports, literature reviews, in vitro studies, animal experiments and articles written in language not compatible with the search strategy adopted in this work were excluded.

RESULTS: Twenty-four articles that met the adopted eligibility criteria were selected, enrolling 3891 subjects under anticoagulant therapy. A total of 171 cases of hemorrhage was observed. Tranexamic acid was the main local hemostatic measure used to controlling of postoperative bleeding.
\end{abstract}

CONCLUSION: The local hemostatic measures proved to be effective according to previously published studies. Nevertheless, further clinical studies should be conducted to confirm this effectiveness.

Key words: Oral Surgical Procedures. Anticoagulants. Hemostatic Techniques. Review. 


\section{Introduction}

In oral surgery, a number of risk factors have been associated with increased risk of bleeding, such as excessive trauma to soft tissues, non-adherence to postoperative instructions, uncontrolled hypertension, as well as anticoagulant therapy ${ }^{1}$. Oral anticoagulants (OA) are drugs commonly prescribed to prevent thromboembolic events associated with important medical conditions, including deep vein thrombosis, pulmonary embolism, valvular disorders, prosthetic heart valves, dilated cardiomyopathy, coronary artery bypass graft, atrial fibrillation, cerebrovascular accident and procoagulation disorder ${ }^{2}$. However, these anticoagulant drugs may predispose patients to developing hemorrhage during or even after minor oral surgery, such as a simple extraction ${ }^{2}$.

In the past few years, altering anticoagulant therapy prior to dental surgery has been an issue of great discussion. Studies have suggested the maintenance of anticoagulant therapy associated with the use of local measures to control bleeding as a safe procedure for performing tooth extractions in anticoagulated patients. Thus, the aim of this study was to perform a systematized literature review regarding the effectiveness of local hemostatic measures to controlling postoperative bleeding in patients undergoing oral surgery without anticoagulant therapy discontinuation.

\section{Methods}

A literature search in the electronic database PubMed was conducted for articles using the following terms (DeCS/MeSH) or combinations with restriction to English, Spanish and Portuguese languages: "oral surgical procedures", "anticoagulants", and "hemostatic techniques". Posteriorly, two reviewers (FSRC and FWGC) independently evaluated the titles and abstracts of the selected articles in a first round of review. In the second round, all articles fulfilling the following eligibility criteria were included: studies involving maintenance of the anticoagulant therapy, prospective studies, retrospective studies, randomized clinical trials, controlled clinical studies, comparative studies, multicentric studies or case-control studies. Studies discontinuing anticoagulant therapy, case reports, literature reviews, in vitro studies, animal experiments and articles written in language not compatible with the search strategy adopted in this work were excluded.

\section{Results}

Initial evaluation identified 615 articles. Twenty-four articles met the eligibility criteria between 1988 and 2011 were selected (Figure 1).

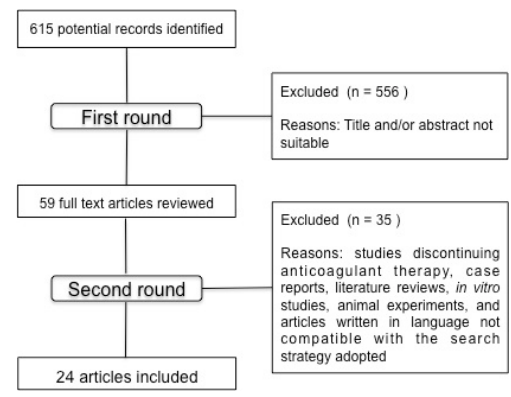

FIGURE 1 - Flow chart of the methodology adopted in the present study.

Of these, 3891 patients under anticoagulant therapy were analyzed according to sex, mean age (years), OA drug, International Normalized Ratio (INR) value before oral surgery, type of surgery, and postoperative medication used for pain control (Tables 1 and 2).

TABLE 1 - Distribution of patients analyzed in each study according to sex, age (mean), and oral anticoagulant (OA).

\begin{tabular}{|c|c|c|c|c|}
\hline Author, year & $\mathbf{N}^{\mathbf{o}}$ & Sex & $\begin{array}{c}\text { Age } \\
\text { (mean) }\end{array}$ & AO \\
\hline Al-belasy, $2003^{16}$ & 40 & $\mathrm{M}(24) / \mathrm{F}(16)$ & 57.22 & Warfarin \\
\hline Bacci, 2010 20 & 900 & $\mathrm{M}(448) / \mathrm{F}(452)$ & 64.95 & Warfarin \\
\hline Bajkin, $2009^{7}$ & 214 & $\mathrm{M}(123) / \mathrm{F}(91)$ & 60.85 & $\begin{array}{l}\text { Acenocoumarol, } \\
\text { warfarin and } \\
\text { phenprocoumarol }\end{array}$ \\
\hline Beirne, $1996^{21}$ & $*$ & $*$ & $*$ & Warfarin \\
\hline Blinder, $2001^{9}$ & 249 & $\mathrm{M}(144) / \mathrm{F}(105)$ & 62 & Coumarin \\
\hline Bodner, $1998^{13}$ & 69 & $*$ & $*$ & $*$ \\
\hline Borea, $1993^{10}$ & 30 & $\mathrm{M}(12) / \mathrm{F}(18)$ & 61.9 & $*$ \\
\hline Cannon, $2003^{8}$ & 70 & $\mathrm{M}(40) / \mathrm{F}(30)$ & 63.3 & Warfarin \\
\hline Carter, $2003^{4}$ & 85 & $\mathrm{M}(54) / \mathrm{F}(31)$ & 65.45 & Warfarin \\
\hline Carter, $2003^{5}$ & 49 & $\mathrm{M}(31) / \mathrm{F}(18)$ & 65 & Warfarin \\
\hline Devani, $1988^{17}$ & 65 & $\mathrm{M}(29) / \mathrm{F}(36)$ & 62.3 & Warfarin \\
\hline Evans, $2002^{18}$ & 109 & $\mathrm{M}(73) / \mathrm{F}(36)$ & 65.55 & Warfarin \\
\hline Ferrieri, $2007^{12}$ & 255 & $*$ & 67.8 & Warfarin \\
\hline Halfpenny, $2001^{2}$ & 46 & $\mathrm{M}(30) / \mathrm{F}(16)$ & 65.65 & Warfarin \\
\hline Hong, $2010^{22}$ & 41 & $\mathrm{M}(21) / \mathrm{F}(20)$ & $*$ & Warfarin and aspirin \\
\hline Morimoto, $2008^{6}$ & 270 & $\mathrm{M}(166) / \mathrm{F}(104)$ & 60.5 & $\begin{array}{l}\text { Warfarin, aspirin, } \\
\text { ticlopidine, cilostazol } \\
\text { and dipyridamole } \\
\text { Warfarin, warfarin }\end{array}$ \\
\hline Morimoto, $2011^{23}$ & 382 & $\mathrm{M}(238) / \mathrm{F}(144)$ & 61.5 & $\begin{array}{l}\text { + antiplalet drug, } \\
\text { antiplalet drug }\end{array}$ \\
\hline Ramström, $1993^{3}$ & 89 & $\mathrm{M}(53) / \mathrm{F}(36)$ & 70.5 & $\begin{array}{l}\text { Phenprocoumarol, } \\
\text { dicumarol and warfarin }\end{array}$ \\
\hline Sacco, $2007^{11}$ & 131 & $\mathrm{M}(66) / \mathrm{F}(65)$ & 62.5 & $\begin{array}{c}\text { Acenocoumarol and } \\
\text { warfarin }\end{array}$ \\
\hline Salam, $2007^{19}$ & 150 & $\mathrm{M}(92) / \mathrm{F}(58)$ & 66.1 & Warfarin \\
\hline $\begin{array}{l}\text { Sindet-Pedersen } \\
1988^{15}\end{array}$ & 39 & $\mathrm{M}(22) / \mathrm{F}(17)$ & 59.6 & $*$ \\
\hline Souto, $1996^{14}$ & 92 & $\mathrm{M}(42) / \mathrm{F}(50)$ & 59.1 & Acenocoumarol \\
\hline Weibert, $1992^{24}$ & 241 & $*$ & $*$ & $*$ \\
\hline Zanon, $2003^{25}$ & 500 & $\mathrm{M}(143) / \mathrm{F}(357)$ & $*$ & Warfarin \\
\hline
\end{tabular}

*Data not informed. 
TABLE 2 - Distribution of patients analyzed in each study according to INR values, type of surgery and postoperative medication for pain control.

\begin{tabular}{|c|c|c|c|}
\hline Author, year & INR (range) & Type of surgery & Pain medication \\
\hline Al-belasy, $2003^{16}$ & $0.9-4.3$ & Simple and complex tooth extraction & Paracetamol \\
\hline Bacci, $2010^{20}$ & $1.01-2.14$ & Dental extractions & $\begin{array}{l}\text { Paracetamol or ibuprofen or } \\
\text { noramidopirin }\end{array}$ \\
\hline Bajkin, $2009^{7}$ & $1.06-4.0$ & Simple tooth extraction & Paracetamol \\
\hline Beirne, $1996^{21}$ & $<4.0$ & * & * \\
\hline Blinder, $2001^{9}$ & $1.5->3.5$ & Simple tooth extraction & $*$ \\
\hline Bodner, $1998^{13}$ & $1.0-5.0$ & Exodontia & * \\
\hline Borea, $1993^{10}$ & $1.5-4.5$ & Exodontia and complex tooth extraction & Paracetamol \\
\hline Cannon, $2003^{8}$ & $1.4-2.1$ & $\begin{array}{l}\text { Simple and complex tooth extraction, biopsy and closure of oroantral } \\
\text { communication }\end{array}$ & $*$ \\
\hline Carter, $2003^{4}$ & $2.7-2.8$ (mean) & Simple tooth extraction & Paracetamol or paracetamol and codeine \\
\hline Carter, $2003^{5}$ & $2.1-4.0$ & Tooth extraction & Paracetamol or paracetamol and codeine \\
\hline Devani, $1988^{17}$ & $1.2-3.9$ & Simple and complex tooth extraction & * \\
\hline Evans, $2002^{18}$ & 1.24 .7 & Simple and complex tooth extraction & Paracetamol \\
\hline Ferrieri, $2007^{12}$ & $1.3-5.4$ & $\begin{array}{c}\text { Simple and complex tooth extraction, biopsy and oral implant } \\
\text { placement }\end{array}$ & $*$ \\
\hline Halfpenny, $2001^{2}$ & $2.0-4.1$ & Simple and complex tooth extraction & $*$ \\
\hline Hong, $2010^{22}$ & $*$ & Single extraction, multiple extractions, biopsy & $*$ \\
\hline Morimoto, $2008^{6}$ & $1.5-3.69$ & Simple and complex tooth extraction & Loxoprofen sodium or paracetamol \\
\hline Morimoto, $2011^{23}$ & $1.50-4.42$ & Tooth extraction & * \\
\hline Ramström, $1993^{3}$ & $*$ & Tooth extraction, impacted tooth surgery and periapical surgery & Paracetamol or dextropropoxifene \\
\hline Sacco, $2007^{11}$ & $1.77-2.89$ (mean) & $\begin{array}{c}\text { Simple and complex tooth extraction, cystic enucleation and oral } \\
\text { implant placement }\end{array}$ & $\mathrm{cos}^{\circ} \mathrm{s}$ \\
\hline Salam, $2007^{19}$ & $<2.5->4.0$ & Simple and complex tooth extraction & * \\
\hline $\begin{array}{l}\text { Sindet-Pedersen } \\
1988^{15}\end{array}$ & $*$ & $\begin{array}{c}\text { Simple tooth extraction, residual root tooth extraction, periapical } \\
\text { surgery and biopsy }\end{array}$ & Paracetamol \\
\hline Souto, $1996^{14}$ & $2.5-3.5$ & Simple tooth extraction & * \\
\hline Weibert, $1992^{24}$ & $*$ & Dental extractions & $*$ \\
\hline Zanon, $2003^{25}$ & $1.8-4.0$ & Surgical extraction, surgical incision of the gun & $\begin{array}{c}\text { Paracetamol or ibuprofen or } \\
\text { noramidopirin }\end{array}$ \\
\hline
\end{tabular}

*Data not informed.

A total of 1851 men and 2040 women with a mean age of 60 years old was observed. The most used anticoagulant drug was warfarin, but the authors also mentioned the use of phenprocoumarol, acenocoumarol, ticlopidine, cilostazol and dipyridamole.

Since there was no pattern for the INR values considered by each author prior to performing oral surgery, this variable was difficult to analyze. However, it was observed that the INR values varied a lot in each study, ranging from 0.9 to 5.4.

The surgical procedures comprised simple and complex exodontia, biopsy, impacted tooth surgery, cystic enucleation, implant placement, closure of oroantral communication, and periradicular surgery. The most used postoperative medication in all of the studies was paracetamol, but other authors ${ }^{3-5}$ prescribed only paracetamol or the association of paracetamol and codeine, and Morimoto ${ }^{6}$ indicated the use of loxoprofen sodium.

A total of 171 cases of hemorrhage was observed. The local hemostatic measures used in anticoagulated patients, number of cases of bleeding in anticoagulated patients and the local hemostatic measures used to stop postoperative bleeding are listed in Table 3. 
TABLE 3 - Distribution of local hemostatic measures used in anticoagulated patients, cases of bleeding in anticoagulated patients, and local hemostatic measures used to stop postoperative bleeding.

\begin{tabular}{|c|c|c|c|}
\hline Author, year & Primary local hemostatic protocol & $\begin{array}{l}\text { Postoperative } \\
\text { bleeding }\end{array}$ & $\begin{array}{l}\text { Secondary local hemostatic } \\
\text { protocol }\end{array}$ \\
\hline Al-belasy, $\mathbf{2 0 0 3}^{16}$ & Cyanoacrylate glue + Suture or Gelatin sponge + Suture & 5 & LITA 2 min + LCG 30 min \\
\hline Bacci, $2010^{20}$ & $\mathrm{OC}+$ Suture or TAGC $30-40 \mathrm{~min}$ & 7 & $\begin{array}{l}\text { Gelatin sponge }+ \text { Suture }+ \\
\text { TAGC }\end{array}$ \\
\hline Bajkin, $2009^{7}$ & Gelatin sponge + Suture & 8 & Suture \\
\hline Beirne, 1996 $^{21}$ & Not reported & Not reported & Not reported \\
\hline Blinder, 20019 & Gelatin sponge + Suture & 30 & $\begin{array}{l}\text { TAGC/Curettage }+ \text { Gelatin } \\
\text { sponge }+ \text { Suture }\end{array}$ \\
\hline Bodner, $1998^{13}$ & Fibrin glue + Suture & 3 & LCG \\
\hline Borea, $1993^{10}$ & TAM $2 \mathrm{~min} / 4 \mathrm{x}$ day/ 7 days & 1 & Not reported \\
\hline Cannon, $\mathbf{2 0 0 3}^{8}$ & $\mathrm{OC}+$ Suture & 9 & LCG \\
\hline Carter, $\mathbf{2 0 0 3}^{4}$ & $\begin{array}{c}\mathrm{OC}+\text { Suture }+\mathrm{TAM} 2 \mathrm{~min} / 4 \mathrm{x} \text { day } / 2 \text { days or OC }+ \text { Suture }+\mathrm{TAM} 2 \mathrm{~min} / 4 \mathrm{x} \\
\text { day } / 5 \text { days }\end{array}$ & 3 & LITA $2 \mathrm{~min}+$ LCG $20 \mathrm{~min}$ \\
\hline Carter, $\mathbf{2 0 0 3}^{5}$ & $\mathrm{OC}+$ Suture $+\mathrm{TAM} 2 \mathrm{~min} / 4 \mathrm{x}$ day $/ 7$ days or $\mathrm{OC}+$ Fibrin glue + Suture & 2 & LCG \\
\hline Devani, $\mathbf{1 9 8 8}^{17}$ & $\mathrm{OC}+$ Suture + LCG $30 \mathrm{~min}$ & 9 & Hospitalization \\
\hline Evans, $2002^{18}$ & $\mathrm{OC}+$ Suture $+\mathrm{LCG} 10 \mathrm{~min}$ & 15 & Suture + LCG \\
\hline Ferrieri, $2007^{12}$ & LITA $(5 \mathrm{ml})+$ Suture + TAGC & 5 & TAGC \\
\hline Halfpenny, 2001² & Fibrin glue / OC & 2 & Hospitalization/Suture \\
\hline Hong, 2010 22 & Gelatin sponge + Suture & 3 & $\begin{array}{l}\text { Gelatin sponge }+ \text { Suture or } \\
\text { Suture }\end{array}$ \\
\hline Morimoto, $\mathbf{2 0 0 8}^{6}$ & $\mathrm{OC}+$ Suture + LCG $30 \mathrm{~min}$ & 11 & $\begin{array}{l}\mathrm{OC}+\text { Suture }+\mathrm{LCG} / \mathrm{LCG}+ \\
\text { Warfarin dose reduction }\end{array}$ \\
\hline Morimoto, $\mathbf{2 0 1 1}^{23}$ & $\mathrm{OC}+$ Suture + Compressed gauze $30 \mathrm{~min}$ & 17 & $\begin{array}{l}\text { Compressed gauze, OC, Suture, } \\
\text { and/or Splint placement }\end{array}$ \\
\hline Ramström, $1993^{3}$ & TAM $2 \mathrm{~min} / 4 \mathrm{x}$ day/7 days & 0 & $\begin{array}{l}\mathrm{LCG}+\mathrm{TAGC} / \mathrm{OC} \text { or Gelatin } \\
\text { sponge }+ \text { Suture }\end{array}$ \\
\hline Sacco, $2007^{11}$ & Gelatin sponge or OC + Suture + TAM $4 \mathrm{x}$ day $/ 2$ days & 10 & Suture + TAM \\
\hline Salam, $2007^{19}$ & $\mathrm{OC}+$ Suture + LCG $10 \mathrm{~min}$ & 10 & $\mathrm{OC}+$ Suture + LCG \\
\hline Sindet-Pedersen $1988^{15}$ & TAM $10 \mathrm{ml} / 2 \mathrm{~min} / 4 \mathrm{x}$ day/ 7 days & 1 & TAGC \\
\hline Souto, $\mathbf{1 9 9 6}^{14}$ & TAM immediately after surgery and TAM $2 \mathrm{~min} / 4 \mathrm{x}$ day $/ 2$ days & 7 & Not reported \\
\hline Weibert, $1992^{24}$ & Not reported & 9 & Not reported \\
\hline Zanon, 2003 25 & $\mathrm{OC}+$ Suture + TAGC 30-60 min & 4 & Gelatin sponge + TAGC \\
\hline
\end{tabular}

TAM, Tranexamic acid mouthwash; OC, Oxidized Cellulose; TAGC, Tranexamic acid saturated gauze compression; LCG, local compression with gauze; LITA, local irrigation with tranexamic acid.

Tranexamic acid (TA) was used as a local hemostatic measure in ten studies. In six studies, TA was associated with other local measures, such as oxidized cellulose (OC) and suture (three studies) or compression with gauze (one study). The ten studies that used TA as a local hemostatic measure associated or not with $\mathrm{OC}$ or hemostatic gauze, which accounted for 2170 patients, reported 35 episodes of bleeding. In four studies that used TA without associations in 250 patients, nine patients had hemorrhage. When TA was associated with other hemostatic measures, episodes of bleeding were observed in 31 out of 1786 patients. OC was used as a local hemostatic measure in nine studies. In five studies it was associated with gauze and suture; in three studies it was used with $\mathrm{TA}$; in one study OC was associated with fibrin glue and another study reported the use of OC associated with suture. A total of 2757 patients used OC associated or not with other hemostatic measures, and 99 episodes of bleeding were observed. In one study, fibrin glue associated with suture was used in 69 patients, and three episodes of bleeding were observed. In three studies, gelatin sponge and suture were used, and 33 episodes of bleeding, out of 290 patients, were recorded. In a study where cyanoacrylate 
glue was used in 40 patients, five patients had hemorrhage. In one study, absorbable collagen sponge was used and, out of 214 patients undergoing oral surgery, eight had hemorrhage. Regarding the local hemostatic measures used to control postoperative bleeding, three studies used TA and six studies used tranexamic acid saturated gauze compression. In seven articles, hemostasis with gauze was reported, which was associated with OC and dose modification of oral anticoagulants in one study. OC was used in two studies, and in one of them, hospitalization of one patient was required. All of the bleeding cases were easily resolved with local hemostatic measures, and systemic uses of vitamin $\mathrm{K}$ or fresh plasma supplementation were not necessary.

\section{Discussion}

Patients undergoing oral surgery who are under anticoagulant therapy to prevent thrombotic events have an increased risk of transoperative and postoperative bleeding, since the anticoagulant therapy has the objective to maintain INR at a therapeutic level and that leads to major bleeding in these patients ${ }^{7}$.

The possibility of postoperative bleeding is a concern for any patient who is under anticoagulant therapy to prevent thrombosis, and usually, these patients are asked to discontinue anticoagulants for a short period of time before surgery ${ }^{8}$. There is no case reported in the literature of life-threatening bleeding in patients who maintained anticoagulant therapy prior to dental surgery. Furthermore, life-threatening cases of thromboembolism after temporarily discontinuing anticoagulants have been reported $^{1,2,9}$.

An increasing number of authors state that oral surgery in anticoagulated patients can be safely performed without discontinuing anticoagulant therapy. They emphasize, though, the use of local hemostatic measures, such as OC (Surgicel), which is dissolved to generate acid and other products that coagulate plasma proteins and hemoglobin to generate a $\operatorname{clot}^{8}$. Absorbable gelatin, or collagen sponges and fibrin glue with sutures are also used as local hemostatic measures ${ }^{7,10,11}$.

Some authors recommend discontinuing anticoagulants and replacing them with heparin. Others recommend reducing anticoagulant therapy prior to surgery and considering an INR range of $1.5-2.0$ as a condition to perform the procedures ${ }^{9,11,12}$. The effectiveness of TA in anticoagulated patients undergoing oral surgery has been reported ${ }^{3,9,13,14}$, as well as the efficacy of fibrin glue, absorbable gelatin, collagen sponges and sutures ${ }^{8-10}$.

In the present study, TA was more effective in controlling hemorrhage when compared to OC and other local measures. The higher effectiveness of TA compared to a placebo has been previously reported by some authors ${ }^{10,15}$ who suggested that the saliva concentration of TA after using it four times a day for rinsing is enough to reduce the incidence of postoperative bleeding complications, according to previously reported results of treatment of hemophilic patients ${ }^{4,5,8,13}$. There does not seem to be any statistically significant difference between a two or five day prescription $^{4}$.

Hemostasis in the oral cavity depends on the dynamic balance between fibrin and plasmin formation, and is influenced by the environment that contains both plasminogen and activated plasminogen $^{3,5}$. TA prevents proteolytic degradation of fibrin, which impairs the fixation of plasminogen and plasmin. A TA solution (4.8\%) has proved to be very effective in reducing bleeding complications with insignificant systemic absorption ${ }^{4}$. The fibrin glue, however, stimulates the last phases of the coagulation cascade, namely the conversion of fibrinogen to fibrin ${ }^{5}$.

The obvious advantage of local inhibition of fibrinolysis in anticoagulated patients is the simplicity and efficacy of the treatment in addition to the lack of serious side effects. The anticoagulant therapy is not discontinued, the patient is not exposed to potential complications such as thromboembolism, and hemostasis can be achieved in a safe and fast way, without major complications as observed in a few cases.

There is controversy in the literature regarding the necessity of discontinuing anticoagulant therapy prior to oral surgery in patients who are at risk for thromboembolism. Preliminary data of this study indicate that there is no need for discontinuing anticoagulation, as long as local hemostatic measures are used ${ }^{10}$.

\section{Conclusions}

Patients under anticoagulant therapy are frequently submitted to oral surgery, which is why the necessity for discontinuing or not anticoagulation poses a dilemma to dentists. Potential risks are involved in this situation, whether it decided to discontinue the medication, which can cause thromboembolism, or maintain therapeutic dose, which can lead to hemorrhage. Considering the data reported in the literature, discontinuing medication does not seem to be necessary, provided that dentists take precautions and use local hemostatic measures efficiently and carefully. However, further clinical studies must be conducted to confirm the effectiveness of these local hemostatic measures. 


\section{References}

1. Scully C, Wolff A. Oral surgery in patients on anticoagulant therapy. Oral Surg Oral Med Oral Pathol Oral Radiol Endod. 2002;94(1):5764.

2. Halfpenny W, Fraser JS, Adlam DM. Comparison of 2 hemostatic agents for the prevention of postextraction hemorrhage in patients on anticoagulants. Oral Surg Oral Med Oral Pathol Oral Radiol Endod. 2001;92(3):257-9.

3. Ramstrom G, Sindet-Pedersen S, Hall G, Blomback M, Alander U. Prevention of postsurgical bleeding in oral surgery using tranexamic acid without dose modification of oral anticoagulants. J Oral Maxillofac Surg. 1993;51(11):1211-6.

4. Carter G, Goss A. Tranexamic acid mouthwash--a prospective randomized study of a 2-day regimen vs 5-day regimen to prevent postoperative bleeding in anticoagulated patients requiring dental extractions. Int J Oral Maxillofac Surg. 2003;32(5):504-7.

5. Carter G, Goss A, Lloyd J, Tocchetti R. Tranexamic acid mouthwash versus autologous fibrin glue in patients taking warfarin undergoing dental extractions: a randomized prospective clinical study. J Oral Maxillofac Surg. 2003;61(12):1432-5.

6. Morimoto Y, Niwa H, Minematsu K. Hemostatic management of tooth extractions in patients on oral antithrombotic therapy. J Oral Maxillofac Surg. 2008;66(1):51-7.

7. Bajkin BV, Popovic SL, Selakovic SD. Randomized, prospective trial comparing bridging therapy using low-molecular-weight heparin with maintenance of oral anticoagulation during extraction of teeth. J Oral Maxillofac Surg. 2009;67(5):990-5.

8. Cannon PD, Dharmar VT. Minor oral surgical procedures in patients on oral anticoagulants--a controlled study. Aust Dent J. 2003;48(2):115-8.

9. Blinder D, Manor Y, Martinowitz U, Taicher S. Dental extractions in patients maintained on oral anticoagulant therapy: comparison of INR value with occurrence of postoperative bleeding. Int J Oral Maxillofac Surg. 2001;30(6):518-21.

10. Borea G, Montebugnoli L, Capuzzi P, Magelli C. Tranexamic acid as a mouthwash in anticoagulant-treated patients undergoing oral surgery. An alternative method to discontinuing anticoagulant therapy. Oral Surg Oral Med Oral Pathol. 1993;75(1):29-31.

11. Sacco R, Sacco M, Carpenedo M, Mannucci PM. Oral surgery in patients on oral anticoagulant therapy: a randomized comparison of different intensity targets. Oral Surg Oral Med Oral Pathol Oral Radiol Endod. 2007;104(1):e18-21.

12. Ferrieri GB, Castiglioni S, Carmagnola D, Cargnel M, Strohmenger $\mathrm{L}$, Abati S. Oral surgery in patients on anticoagulant treatment without therapy interruption. J Oral Maxillofac Surg. 2007;65(6):1149-54.

13. Bodner L, Weinstein JM, Baumgarten AK. Efficacy of fibrin sealant in patients on various levels of oral anticoagulant undergoing oral surgery. Oral Surg Oral Med Oral Pathol Oral Radiol Endod. 1998;86(4):421-4.

14. Souto JC, Oliver A, Zuazu-Jausoro I, Vives A, Fontcuberta J. Oral surgery in anticoagulated patients without reducing the dose of oral anticoagulant: a prospective randomized study. J Oral Maxillofac Surg. 1996;54(1):27-32.

15. Sindet-Pedersen S, Ramstrom G, Bernvil S, Blomback M. Hemostatic effect of tranexamic acid mouthwash in anticoagulant-treated patients undergoing oral surgery. N Engl J Med. 1989;320(13):8403.

16. Al-Belasy FA, Amer MZ. Hemostatic effect of n-butyl-2cyanoacrylate (histoacryl) glue in warfarin-treated patients undergoing oral surgery. J Oral Maxillofac Surg. 2003;61(12):14059.

17. Devani P, Lavery KM, Howell CJ. Dental extractions in patients on warfarin: is alteration of anticoagulant regime necessary? Br J Oral Maxillofac Surg. 1998;36(2):107-11

18. Evans IL, Sayers MS, Gibbons AJ, Price G, Snooks H, Sugar AW. Can warfarin be continued during dental extraction? Results of a randomized controlled trial. Br J Oral Maxillofac Surg. 2002;40(3):248-52.

19. Salam S, Yusuf H, Milosevic A. Bleeding after dental extractions in patients taking warfarin. Br J Oral Maxillofac Surg. 2007;45(6):4636.

20. Bacci C, Maglione M, Favero L, Perini A, Di Lenarda R, Berengo M, Zanon E. Management of dental extraction in patients undergoing anticoagulant treatment. Results from a large, multicentre, prospective, case-control study. Thromb Haemost 2010;104(5):9725.

21. Beirne OR, Koehler JR. Surgical management of patients on warfarin sodium. J Oral Maxillofac Surg 1996;54:1115-1118.

22. Hong CH, Napenas JJ, Brennan MT, Furney SL, Lockhart PB. Frequency of bleeding following invasive dental procedures in patients on low-molecular-weight heparin therapy. J Oral Maxillofac Surg. 2010;68:975-9.

23. Morimoto $\mathrm{Y}$, Niwa $\mathrm{H}$, Minematsu $\mathrm{K}$. Risk factors affecting postoperative hemorrhage after tooth extraction in patients receiving oral antithrombotic therapy. J Oral Maxillofac Surg. 2011;69:15506.

24. Weibert RT. Oral anticoagulant therapy in patients undergoing dental surgery. Clin Pharm. 1992;11(1):857-64.

25. Zanon E, Martinelli F, Bacci C, Cordioli G, Girolami A. Safety of dental extraction among consecutive patients on oral anticoagulant treatment managed using a specific dental management protocol. Blood Coagul Fibrinolysis. 2003;14:27-30.

\section{Correspondence:}

Fábio Wildson Gurgel Costa

Rua João Sorongo, 1016/205

60416-000 Fortaleza - CE Brasil

Tel.: (55-85)88191364

fwildson@yahoo.com.br

Received: August 15, 2012

Review: October 17, 2012

Accepted: November 18, 2012

Conflict of interest: none

Financial source: none

${ }^{1}$ Research performed at School of Dentistry, Postgraduate Program in Dentistry, Dental Clinic Area, Federal University of Ceara (UFC), Fortaleza-CE, Brazil. 